\title{
13. Assessing the Shift to Limited Preferential Voting
}

\author{
R.J. May, Katherine Wheen and Nicole Haley ${ }^{1}$
}

As part of a package of economic and political reforms, the Morauta government of 1999-2002 amended the Organic Law on National and Local-level Government Elections to replace the existing first-past-the-post (FPTP) voting system to one of limited preferential voting (LPV). ${ }^{2}$ This did not come into effect in the national election of 2002, but was used in 10 by-elections between 2002 and 2007.

Under the new LPV system voters were required to express three preferences. ${ }^{3}$ Once transferred, second and third preferences carried the same weight as a first preference. Failure to express three preferences constituted an invalid vote.

A number of reasons was given for the decision to change to LPV. ${ }^{4}$ First and foremost, there had been growing concern that, with increasing numbers of candidates contesting successive elections (in 2002 the average number of candidates per electorate had risen to 26, with a record of 62 in Oro Provincial), and a weak party vote, members were being elected with increasingly small shares of the vote. In 2002, 22 MPs (20 percent) were elected with less than 10 percent of the vote and 62 MPs (57 percent) with less than 20 percent, the lowest winning vote being 6 percent in Oro Provincial; the average winning vote was 19.7 percent. ${ }^{5}$ This meant that MPs could be said to have only a 'small mandate' (Somare once referred to the national parliament as a 'house of rejects' (quoted in Post-Courier 7 September 1999). Because LPV would produce what was commonly referred to as an 'absolute majority', and thus 'promote the election of more broadly supported candidates' (Reilly 2006:189), it was argued that LPV

\footnotetext{
1 The authors gratefully acknowledge Bill Standish's comments on a draft of this paper.

2 Prior to independence in 1975 there had been an optional preferential voting system, though most voters had opted not to exercise their preferences beyond the primary vote.

3 In the 10 by-elections, candidates were required to mark their ballot papers, which listed all candidates with accompanying photographs, with the numbers 1, 2 and 3 alongside their preferred candidates. In 2007 the format of the ballot paper was changed; posters showing the list of numbered candidates were displayed in all polling booths and voters were given ballot papers with three spaces, numbered 1, 2, 3, against which they had to write the numbers and/or names of their preferred candidates.

4 For a more detailed discussion see Standish (2006). A major proponent of this 'social engineering' was The Australian National University academic Ben Reilly (see Reilly 1996, 2001a, 2002, 2004, 2006). More sceptical views were expressed by May (2000) and Standish (2002), as well as by the former electoral commissioner, Reuben Kaiulo (Kaiulo 2002:179).

5 Calculated from the official results of the 2002 election, released by the Papua New Guinea Electoral Commission. Results were available for 103 seats only, with the 6 failed election results excluded.
} 
would yield better MPs with a 'stronger mandate'. ${ }^{6}$ It was not generally made clear, however, that what LPV produced was a majority -50 percent +1 - of live votes at the final count after eliminations, which, as will be seen below, may be well below 50 percent of the total number of valid votes cast. Secondly, in many electorates, especially in Highlands open electorates, the distribution of votes between a large number of candidates meant that a candidate who could hold together a relatively small clan or 'base' vote could have enough votes to win. ${ }^{7}$ This encouraged such malpractices as voter intimidation, enforced bloc voting, and discouraging outsiders from campaigning in a candidate's home area-which in turn resulted in confrontational and often violent behaviour. LPV, it was widely believed, would lead to more accommodative behaviour, partly through preference-swapping alliances between candidates, particularly candidates from across regional, clan or 'ethnic' boundaries, and thus more orderly and peaceful elections. Thirdly, the fact that voters could express a preference for three candidates meant that voters who were under pressure from family, clan or others to vote for a candidate not of their choosing might be able to meet this obligation but then allocate their second and third preferences to candidates of their choice. This was particularly relevant for women, who were often obliged to vote as their husbands or male relatives dictated, and was seen as likely to benefit women candidates. Some people suggested that LPV would bring about a reduction in the number of candidates - though it was never explained why that would happen - and that it would strengthen political parties by encouraging electoral alliances between parties. In short, in the words of Electoral Commissioner Andrew Trawen, 'LPV voting, we hope, will change the mindset of our people' (Trawen 2006:3).

Between 2003 and 2006 ten by-elections under LPV were held, in Abau (2003), Angalimp-South Wahgi, Chimbu Provincial, Yangoru-Saussia, Moresby Northeast, Wabag (all 2004), Bougainville Provincial, NCD Provincial, KorobaLake Kopiago and Chuave (all 2006). An audit of three by-elections in mid-2004 (Angalimp-South Wahgi, Chimbu Provincial and Yangoru-Saussia) concluded that, despite some problems, particularly due to inflated electoral rolls, the byelections were generally peaceful, though this may have had more to do with heavy security than with the new voting procedures (Institute of Policy Studies et al. 2004). A subsequent analysis by Bill Standish of the first six by-elections (these three plus Abau, Moresby Northeast and Wabag) sought to identify 'some early lessons' from the LPV experience. Among Standish's conclusions were:

6 As May (2000) has pointed out, however, the largest mandate ever received by a Papua New Guinean MP - 83 percent of the vote - was that received by cult leader Mathias Yaliwan in Yangoru-Saussia in 1972, but Yaliwan subsequently lost his seat for not attending parliament - scarcely an endorsement for large mandates! 7 For example, in an electorate of say 30,000 voters with say 40 candidates, a contest could theoretically be won with as few as 751 votes. 
- 'Many candidates had limited understanding of the significance of preferences, and most only campaigned locally, just as they had under FPTP'

- '... not all candidates had the ability to direct preferences towards allies ... some candidates directed their supporters to give their preferences to minor candidates'

- 'Campaigning was much more relaxed and accommodative'

- the 'polls were less violent ... [and] the levels of intimidation were greatly reduced compared with 2002' (noting, however, 'the strong police presence' and that, as mid-term by-elections, 'the stakes [were] not as high')

- voters spoke 'enthusiastically about having a "free" second and third choice' (though 'in certain areas the primary vote was filled out by the presiding polling official')

- 'For women, voting is more free under LPV, at least for second and third preferences', though in Abau women said 'they had followed family decisions on how to allocate preferences', and the primary vote for women candidates remained very low

- the 'overall mandates' (primary votes plus preferences as a percentage of total valid votes in the initial count) of the new MPs were nearly doubled; nonetheless, in four cases the mandates ranged from 22 to 29 percent - the count being drawn out till the third last candidate was eliminated-and in the other two were 'around 50 percent'.

Standish also noted that there were fewer candidates in the by-elections (though still, on average, more than 20) but that this was normal for by-elections, and that there was little sign that the Organic Law on the Integrity of Political Parties and Candidates had changed people's voting behaviour towards political parties. Overall, his evaluation was that 'LPV has had some real success ... [but] has not achieved the exaggerated hopes of its proponents'. (See Standish 2006.)

\section{LPV in 2007}

\section{Awareness and training of polling and counting officials}

Apart from those electorates in which by-elections were held under LPV, there were relatively few voters who would have retained a memory of optional preferential voting before 1975. Thus, in the lead-up to the election, electoral awareness campaigns were mounted, by both the Papua New Guinea Electoral Commission (PNGEC) and civil society organizations, to prepare voters and candidates for the introduction of the new voting system in 2007. (The AusAID- 
funded voter education program is discussed specifically in chapter 4.) While these campaigns gave some attention to broader aspects of the election, such as the need for voters to choose candidates who possessed good leadership qualities, they were directed essentially at the more technical aspects of LPV, specifically how to cast a valid vote. And for the most part their coverage seldom reached to the more remote parts of electorates. Subsequently, during campaigning most candidates helped to educate voters about LPV, but again the focus was on making sure that potential supporters' votes counted rather than on how preferences might be effectively used. Notwithstanding this, some candidates seem to have had a poor understanding of how LPV worked: observers reported cases in which candidates were under the apparent impression that all three preferences of all voters were totalled to give a final vote, and one candidate who should have known better complained, 'As the rule had it, elimination began immediately after the conclusion of the count on first preferences. This immediately rendered the secondary and third preferences of the eliminated candidates useless - exhausted votes' (Digim'Rina 2007:34).

Training was also conducted for polling officials and counting officials to familiarize them with LPV procedures. The reports of observers involved in the Domestic Observer exercise suggest that in several instances this training was not adequate, but in general there seems to have been a good understanding of the technical aspects of the poll, and in most electorates the distribution of preferences seems to have proceeded fairly smoothly. Some commentators have cited, as an indicator of the administrative success in introducing LPV, the generally low informal vote (for the 102 electorates for which data was available at December 2010, the national average was 2.1 percent); as others have pointed out, however, low informal voting might also be explained by the prevalence, especially in Highlands electorates, of bloc voting (or 'controlled voting') and assisted voting. While assistance was often needed to enable illiterate or confused voters to cast their vote, candidate supporters (including, in some instances, polling officials) sometimes used this to deprive voters of their free choice. Thus, informal voting was lowest in the remote Kandep and Jimi open electorates ( 0.3 percent) and averaged 1.3 in the Highlands Region, but was 3.3 percent in the relatively well-educated Islands Region and highest in the National Capital District (5.7 percent) (Anere and Wheen 2009:27).

These aspects of the election are discussed in more detail elsewhere in this volume and in the Domestic Observation Report (Haley and Anere 2009:33-36). 


\section{LPV and candidate strategies}

One of the most common arguments put forward in support of LPV was that, because candidates would need to secure preferences outside their base support areas, it would encourage cooperative behaviour among candidates, and thereby reduce tensions associated with electoral competition. FPTP voting, it was argued, was a highly competitive process and encouraged behaviour of the type that had characterized earlier elections in some parts of Papua New Guinea, particularly in the Highlands, where candidates or their supporters had blocked roads, fired on helicopters, and taken other extreme measures to prevent rival candidates from entering the candidate's 'support base', not to mention hijacking ballot boxes from the home areas of rival candidates. In fact, under FPTP it was not uncommon for stronger candidates to put up 'dummy candidates' in the home areas of rival candidates to split their vote - which might be described as a form of 'cooperative' behaviour, albeit a negative one. The expectation was, however, that with the introduction of LPV, candidates would form cooperative alliances to exchange preferences with other candidates of similar interests but (usually) different support bases, and in this way reduce confrontational behaviour and promote more peaceful elections.

Reporting on Abau in 2007, Anere observes that 'candidates saw the need to exchange second and third preferences and in some instances campaigned for each other in areas that were not their strongholds', though 'most ran their campaigns independently of each other'. Generally, however, there was not much evidence of cooperative preference swapping. In Oro (where there was a strong 'Oro for Oro' campaign) and Madang there were reports of 'ethnic' alliances among local groups seeking to resist the influence of candidates whose origins lay outside the province ('outsiders') (see chapters 15 and 21), and there may have been similar ethnic cooperation among candidates in parts of several other electorates (see, for example, Sepoe [chapter 10] on inland versus coastal voting in Kerema Open, and Kinkin [chapter 25] on Baining versus Tolai voting in Gazelle Open), and among 'outsider' groups in provinces like Madang and Oro. There were also instances (including East Sepik and East New Britain provincial electorates) in which several candidates 'ganged up' against a sitting member (as has occurred in elections prior to the introduction of LPV). But where such cooperation did take place it appears to have been mostly unorganized and informal and did not involve formal exchanges of preferences (over which candidates had little control anyhow).

In Australia's preferential voting system it is customary for most parties to hand out to voters a 'how-to-vote card', which indicates where the candidatewho generally represents a party-recommends preferences should go, in accordance with (party) strategy. But in Papua New Guinea this would be a 
dangerous strategy. Since the party system is poorly developed and voting is significantly localized and personalized, and given that in most electorates there is a large number of candidates, candidates are unlikely to risk alienating voters by telling them how they should allocate their preferences. Rather, if a candidate is campaigning in a place (typically a village or settlement) where he/ she expects to get strong support he/she will usually ask for the first preference but not presume to tell voters where their other preference should go; if he/ she is campaigning in a place where he/she knows that voters are likely to vote for another candidate, he/she will generally acknowledge that, and modestly ask for voters' second or third preferences. The candidate's strategy will thus vary according to the local situation; a generalized how-to-vote approach is not appropriate. ${ }^{8}$ This was evidenced in the candidates' posters which were on display on buildings and trees in villages and towns: the great majority urged voters to 'Vote 1 ' for the candidate, but indicated no second or third preferences. Even in an electorate like East Sepik Provincial, where coalition partners had resolved not to endorse candidates against Prime Minister Sir Michael Somare and the 10 other candidates were all broadly 'anti-Somare', there was some collaboration between candidates opposing the sitting member, and a natural flow of preferences among the 10, but no coherent strategy of preference swapping.

In most electorates, indeed, observers reported that when pressed on the question of preference strategies most candidates with an expectation of election told voters to give them the first preference (or second if there was a favoured local son or daughter) and give the other preferences to minor candidates (or rabis candidates) who were not likely to threaten the candidate's chance of election. (This was, of course, more of a 'spoiling tactic' than a rational strategy, since so long as the candidate remained in contention his/her second and third preferences were irrelevant.)

There were suggestions, however, that in those electorates which had experienced by-elections under LPV, voters tended to act more 'strategically', directing their votes to candidates with a broader support base. The primary evidence for this was a lower proportion of exhausted ballots. (This is discussed further below.)

\section{The impact of LPV on the election}

It is difficult to say how the impact of LPV should be measured.

8 Indeed, there have been instances in Australian elections in which parties have distributed different howto-vote cards in different parts of an electorate. 
One obvious approach is to look at the candidates who were leading on first preferences - and who might therefore have won under FPTP voting - and see how many of these were eventually successful when preferences had been distributed. As at December 2010, complete results were not available, but for the 102 electorates for which data was available, ${ }^{9} 80$ candidates who were in front on first preferences maintained their lead to become eventual winners. Of these 40 (half) were sitting members. Of the remaining 22 candidates who gained the largest share of first preference votes but subsequently lost on preferences, 7 were sitting members. They included former prime minister and Pangu Pati leader in 2007 Sir Rabbie Namaliu, who lost his seat in Kokopo, and former prime minister and People's Democratic Movement leader Paias Wingti, who had lost his seat in 1997 but had been re-elected in 2002. Wingti was leading the count up till the last distribution of preferences but lost by a narrow margin when his rival, Tom Olga, received the bulk of the preferences. This result, also, was subsequently challenged, and was not resolved until after a second recount in 2010, which confirmed Olga's victory.

In several other instances, sitting members who were leading on the primary count held on to win, but saw a strong movement of preferences against them. For example, Prime Minister Sir Michael Somare received a healthy 36 percent of the primary vote in East Sepik Provincial, well ahead of his nearest rival, who received 16 percent, but facing a virtual 'anti-Somare' coalition he received only 14 percent of preference votes compared to the runner-up, Moses Murray, who received 39 percent (see chapter 25, Table 25.1). In Moresby South, Dame Carol Kidu saw her lead of 1877 on first preferences whittled away by Pangu Pati challenger Justin Tkatchenko as preferences were tallied, but held on to win.

According to preliminary figures supplied to the National Research Institute by the PNGEC, only four candidates (William Duma [Hagen Open], Don Polye [Kandep Open], Patrick Pruaitch [Aitape-Lumi Open] and Peter O'Neill [IalibuPangia Open]) won an absolute majority of first preferences. In Kandep, Polye, the sitting member, was declared winner with 69 percent of the primary vote, but soon after the declaration an electoral official in Kandep was charged with offences under the Organic Law, and the election result was disputed by the runner-up, Alfred Manase. A by-election was held in November 2009 but in the face of local violence voting did not take place in three polling places and counting was moved out of the province due to security concerns. Polye was eventually returned, winning 53 percent of first preference vote.

Perhaps the strongest reason given in support of LPV was that it would 'increase the mandate' of elected MPs. Much was made, over the period 2002-2007, of the

9 The following analysis uses both figures supplied by the PNGEC and, where official figures were not available, unofficial figures collected by domestic observers. Some of the data remains provisional. 
claim that under LPV all elected MPs would have at least ' 50 percent +1 ' of the vote. This claim, made by the PNGEC among others, was, of course, misleading. While it is true that under LPV successful candidates must receive a majority of the 'live votes', with only three preferences and a large number of candidates it was inevitable that a proportion of the ballot papers would become 'exhausted' before a final result emerged, that is, there would be ballot papers with votes for three candidates all of whom had been eliminated relatively early in the count. A more meaningful measure of a successful candidate's 'mandate' is the total of first, second and third preferences received by the candidate, expressed as a percentage of the total allowable ballots cast. When these figures are examined, it is evident that while a majority of candidates won with between 20 and 40 percent of the total votes, and some with less, the national average mandate (for the 102 seats for which data was available) was 33 percent. Given that LPV is bound to give a larger 'mandate' than a FPTP simple majority, this result was seen as a marked improvement on 2002 outcomes under FPTP (20.5 percent)though still well short of 50 percent.

Interestingly, figures of primary votes also show fewer candidates leading with small first preference totals in 2007 compared to the totals of winning candidates under FPTP in 2002: 10 percent won the primary vote in their seats with less than 10 percent of the primary vote in 2007 compared to 21 percent winning with less than 10 percent in 2002, and 54 percent won the primary vote with less than 20 percent in 2007 compared to 60 percent in $2002 .{ }^{10}$

Analysis of 'mandates' and percentages of exhausted ballot papers by electorate and region, reveals some variation across the country. For the 102 electorates for which data was available, the regional average mandate was, perhaps predictably, highest in the Islands Region (40 percent) but surprisingly uniform in the other three regions (31 percent in both Momase and the Highlands and 32 percent in the Southern Region). The average proportion of exhausted ballot papers was high throughout the Highlands, Southern and Momase regions (44, 43 and 42 percent respectively) and lowest in the Islands (26 percent). ${ }^{11}$ These rankings roughly correlated with the regional average numbers of candidates: 28 in Highlands, 29 in Southern, 25 in Momase, and a relatively low 14 in the Islands. Further evidence of a the link between the number of candidates and the number of exhausted ballots was shown in the fact that in the 22 electorates with more than 60 percent of exhausted ballot papers there were on average 41 candidates, whereas in the 22 electorates with less than 20 percent of exhausted ballots the

10 The average share of the primary vote of those leading on the primary vote (but not necessarily winning the seat) in 2007 was 22.5 percent; the average share of the primary vote of the eventual winners (some of whom were behind on the first preference count) was slightly less at 21.9 percent. This compares with the average winning vote in 2002 , of 20.5 percent.

11 Sixteen electorates recorded in excess of 50 percent exhausted ballot papers; half of these were in the Highlands Region. 
average number of candidates was 13. Mandates were higher and exhausted ballots lower in provincial seats ( 41 percent and 26 percent respectively) than in open seats (30 percent and 43 percent). There is some evidence that those electorates which had experienced by-elections under LPV produced winners with larger mandates (and larger proportions of the primary vote) and fewer candidates than those which had not, but the evidence is weak: six of the ten did, four did not.

Table 13.1: Limited preferential voting comparison between by-elections and general elections

\begin{tabular}{|c|c|c|c|c|c|c|}
\hline \multirow[b]{2}{*}{ Electorate } & \multicolumn{3}{|c|}{ LPV by-election } & \multicolumn{3}{|c|}{2007 general election } \\
\hline & $\begin{array}{l}\text { Number of } \\
\text { candidates }\end{array}$ & $\begin{array}{c}\text { Primary } \\
\text { vote }(\%)^{\mathrm{a}}\end{array}$ & $\begin{array}{l}\text { Mandate } \\
\text { (\%) }\end{array}$ & $\begin{array}{l}\text { Number of } \\
\text { candidates }\end{array}$ & $\begin{array}{l}\text { Primary } \\
\text { vote }(\%)^{\mathrm{a}}\end{array}$ & $\begin{array}{c}\text { Mandate } \\
(\%)\end{array}$ \\
\hline Chimbu Provincial & 31 & 13 (1st) & 21 & 19 & 18 (1st) & 39 \\
\hline NCD Provincial & 23 & 23 (1st) & 38 & 7 & 41 (1st) & 49 \\
\hline $\begin{array}{l}\text { Bougainville } \\
\text { Provincial }\end{array}$ & 6 & 38 (1st) & 55 & 8 & 27 (1st) & 46 \\
\hline Chuave Open & 24 & 13 (2nd) & 20 & 29 & 16 (1st) & 32 \\
\hline $\begin{array}{l}\text { Koroba-Lake } \\
\text { Kopiago Open }\end{array}$ & 20 & $12(3 r d)$ & 30 & 17 & 18 (1st) & 37 \\
\hline Wabag Open & 19 & 38 (1st) & 48 & 19 & 34 (1st) & 45 \\
\hline $\begin{array}{l}\text { Angalimp- South } \\
\text { Wahgi Open }\end{array}$ & 30 & na & & 24 & na & \\
\hline $\begin{array}{l}\text { Moresby North- } \\
\text { East Open }\end{array}$ & 22 & 16 (1st) & 28 & 31 & 13 (1st) & 24 \\
\hline $\begin{array}{l}\text { Yangoru-Saussia } \\
\text { Open }\end{array}$ & 18 & 19 (1st) & 30 & 15 & 25 (1st) & 33 \\
\hline Abau Open & 6 & 49 (1st) & 50 & 12 & 43 (1st) & 49 \\
\hline
\end{tabular}

na $=$ not available

$a$ The 1st, 2nd or 3rd in parentheses refers to the candidate's placing after the primary vote

$b$ 'Mandate' refers to winning candidate's percent of allowable papers

Source: Adapted from Haley and Anere (2009:71-77) with additional data from PNGEC results tables

A particular question raised by the shift to LPV was whether the new system would benefit female candidates, since women voters who were constrained by customary obligation or intimidation to vote for a male candidate might be able to give second or third preference to a female candidate. The data is inconclusive. In East Sepik Provincial, Elizabeth Simogun Bade secured a good preference vote, almost certainly reflecting preferences from women voters, but did not poll strongly enough in the primary count to take advantage of this (a pattern already seen in the earlier by-elections in Angalimp-South Wahgi and Yangoru-Saussia). On the other hand, in Moresby South Dame Carol Kidu, who 
had a clear lead on first preferences, received significantly fewer second and third preferences than her nearest, male, rival. In Kerema, where three women candidates stood, there was no evidence that women candidates attempted to direct preferences towards the other women candidates, or even that women voters supported women candidates (see, for example, chapters 10, 22 and 27).

Overall, a number of candidates, voters and observers did express the view that the 2007 election under LPV was a 'more friendly election' than those of 2002 and 1997, that candidates felt more free to move around the electorate without harassment and on occasion share a platform with rival candidates, and that LPV gave electors 'more choice', particularly significant in places where voters (especially women voters) were under pressure to support a communally chosen candidate. ${ }^{12}$ There appears to have been less election-related violence in 2007 than there was in 2002 - especially in the Southern Highlands, where elections in six electorates had been declared 'failed elections' in 2002 but things went relatively peacefully in 2007-although this was almost certainly due in large part to the heavy and well-coordinated presence of the security forces in 2007 (see chapters 6, 7 and 8). Nevertheless, in Chimbu there were at least three polling-day murders and almost as many post-election deaths as in 2002-19 compared with about 25 (Bill Standish, personal communication September 2009).

With regard to the other hoped-for benefits from the shift to LPV, there was little evidence that LPV reduced the number of candidates (which was slightly smaller in 2007 than in 2002, but still high, at 2759), or that it did anything to strengthen parties (see chapter 9).

\section{Conclusion}

To the extent that almost a quarter of candidates leading on first preferences subsequently lost, it appears that LPV did produce different outcomes from what would have been produced by a FPTP contest. This was an implicit aim of the shift to LPV, but it was not overwhelmingly welcomed, particularly after Namaliu lost his seat on the preference count, prompting some observers to question the assumption that LPV, with its 'stronger mandate', necessarily produced 'better' MPs. In 2008, the then registrar of political parties, Paul Bengo, voiced

12 Bill Standish, however, suggests that in the Highlands most people followed group decisions about preferences as well as primary votes, and that ballots were frequently checked or 'controlled' by 'helpers' at the polling booths (personal communication, September 2009). 
some disappointment at the outcomes in some seats, and suggested that perhaps thought should be given to a weighted preference system, in which second and, a fortiori, third preferences should count for less than a first preference vote. ${ }^{13}$

The general consensus seems to be that LPV has been a qualified success, though it has not, at this stage, done much to change deeply rooted patterns of behaviour in much of the country. LPV offered more choice, though this was frequently compromised by the lack of a genuinely secret ballot. Campaigning was generally more accommodative - but with 'no distinctive evidence of any successful strategic alliances' (Anere and Wheen 2009:21)-and less violent, though this may been due more to the more extensive security operation than to the new voting system. Mandates increased, as was to be expected of the new electoral arithmetic, though it remains to be seen whether this will yield better MPs. Otherwise, there was slight evidence that LPV had benefited women (at least 10 women received more than 10 percent of the primary vote [after redistribution of preferences], compared to one in 2002), and little to support the beliefs that it would reduce the number of candidates or strengthen political parties. Undoubtedly, as former electoral commissioner Reuben Kaiulo observed in 1997 (Kaiulo 2002:179), preferential voting is more complex than FPTP, and poor understanding of the system in some electorates resulted in errors in counting and delays in finalizing results.

More dramatic improvements in electoral performance will require not just changes in electoral procedures, important though these may be, but radical shifts in deeply rooted patterns of behaviour. As Standish warned in 2006, 'we should not expect revolutionary changes overnight' (2006:202). In its analysis of LPV in the 2007 election, a National Research Institute report concluded, 'Electoral engineering is not a silver bullet to governance problems. The system alone is only going to have a limited impact on improving the quality of candidates, the reasons why voters make their choices, and the quality of the MPs who are elected, in the context of the high-stakes political culture in PNG' (Anere and Wheen 2009:20).

13 Such a system - the Borda count, named after the eighteenth-century French mathematician, JeanCharles de Borda, who first proposed it - has been used in Nauru. See Reilly (2001b). 


\section{References}

Anere, R. and Wheen, K., 2009. Priorities for a Free and Fair Election: An NRI Issues Analysis. Discussion Paper No. 107. Port Moresby: The National Research Institute.

Digim'Rina, L. S., 2007. 'Fishermen do not fish without obligation: prostitution of voters, candidates, kastom, and state processes - the case of Kiriwina-

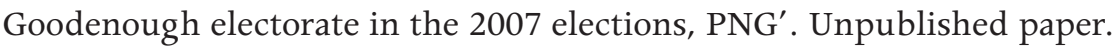

Haley, N. and Anere, R., 2009. The 2007 Papua New Guinea National General Elections: Domestic Observation Report. Special Publication No. 52. Port Moresby: The National Research Institute.

Institute of Policy Studies, Victoria University, New Zealand, Papua New Guinea Institute for National Affairs and Transparency International (PNG), 2004. The Election Audit Report. Election Lessons Prepared for the PNG Electoral Commission on 3 By-elections held in Papua New Guinea in mid 2004. Wellington: Victoria University.

Kaiulo, R., 2002. 'Report to the Sixth Parliament on the 1997 National Election by the Electoral Commissioner', in R. J. May and R. Anere (eds), Maintaining Democracy: The 1997 Elections in Papua New Guinea. Port Moresby: Department of Political Science, University of Papua New Guinea, and State, Society and Governance in Melanesia Project, The Australian National University, pp. 169-180.

May, R. J., 2000. 'Political change in Papua New Guinea: is it needed? Will it work?' Keynote address to conference at Divine Word University, Madang. Unpublished.

Reilly, B., 1996. 'The effects of the electoral system in Papua New Guinea', in Y. Saffu (ed.), The 1992 Papua New Guinea Elections: Change and Continuity in Electoral Politics. Canberra: Research School of Pacific and Asian Studies, The Australian National University, pp. 43-76.

Reilly, B., 2001a. Democracy in Divided Societies: Electoral Engineering for Conflict Management. Cambridge: Cambridge University Press.

Reilly, B., 2001b. 'The Borda count in the real world: the electoral system in the Republic of Nauru'. Working Paper 8. Christchurch: Macmillan Brown Centre for Pacific Studies, University of Canterbury.

Reilly, B., 2002. 'Electoral systems for divided societies', Journal of Democracy 13(2):156-170. 
Reilly, B., 2004. 'The global spread of preferential voting: Australian institutional imperialism?', Australian Journal of Political Science 39(2):253-266.

Reilly, B., 2006. 'Political reform in Papua New Guinea: testing the evidence', Pacific Economic Bulletin 21(1):187-194.

Standish, B., 2002. 'Papua New Guinea politics: attempting to engineer the future', Development Bulletin 60:28-32.

Standish, B., 2006. 'Limited preferential voting in Papua New Guinea: some early lessons', Pacific Economic Bulletin 21(1):195-211.

Trawen, A., 2006. 'Electoral reforms: implications for the 2007 national elections', in 'Two papers on electoral reform in Papua New Guinea'. Public Policy in Papua New Guinea Discussion Paper 2006/3. Canberra: National Research Institute, Papua New Guinea, and State, Society and Governance in Melanesia Program, The Australian National University. 